\title{
The Efficiency by Which Thrips tabaci Populations Transmit Tomato spotted wilt virus Depends on Their Host Preference and Reproductive Strategy
}

\author{
Elisavet K. Chatzivassiliou, Dick Peters, and Nikolaos I. Katis
}

First and third authors: Plant Pathology Laboratory, Aristotle University, Faculty of Agriculture, P.O. Box 269,540 06 Thessaloniki, Greece; and second author: Laboratory of Virology, Agricultural University, Binnenhaven 11, 6709 PD, Wageningen, The Netherlands. Accepted for publication 14 February 2002.

\begin{abstract}
Chatzivassiliou, E. K., Peters, D., and Katis, N. I. 2002. The efficiency by which Thrips tabaci populations transmit Tomato spotted wilt virus depends on their host preference and reproductive strategy. Phytopathology 92:603-609.

Arrhenotokous and thelytokous populations of Thrips tabaci from tobacco or leek plants were evaluated for their ability to transmit Tomato spotted wilt virus (TSWV) and for their host preference. Transmission efficiencies were comparatively studied using leaf disks of Petunia hybrida, Datura stramonium, and Nicotiana tabacum cv. Basmas. Adults of arrhenotokous populations collected on infected tobacco plants in the field were efficient transmitters (up to $48.5 \%$ transmission) and remained so when maintained on tobacco for several generations. Arrhenotokous $T$. tabaci populations from leek plants were poor transmitters (up to $3.1 \%$ transmission), whereas no transmission was obtained with thelytokous

val instars of a T. tabaci population from tobacco. However, the transmission by adults decreased with the age at which the virus was acquired by larvae. The highest efficiencies $(61 \%$ of males and $51 \%$ of females transmitted) were obtained when newborn (0- to 24-h old) larvae acquired the virus. The majority of thrips started to transmit after becoming adult and rates were positively correlated with the temperature at which the thrips were kept. The median latent period values found for adults decreased with increasing temperature. The median acquisition access period $\left(\mathrm{AAP}_{50}\right)$ of the population was $41 \mathrm{~min}$, whereas the $\mathrm{AAP}_{50}$ was 65 min for males and 35 min for females. The median inoculation access period of males was 246 and 365 min on tobacco and petunia, respectively, and 96 and $345 \mathrm{~min}$ for females. The results show that $T$. tabaci forms a complex in terms of host preference, reproductive strategy, and ability to transmit TSWV. The transmission parameters show that the thrips of arrhenotokous populations infesting tobacco are highly efficient vectors.
\end{abstract} populations from leek. All populations could infest leek, however none of the arrhenotokous and thelytokous populations from leek plants was able to infest tobacco. TSWV could be acquired by both first and second lar-
Additional keywords: leek thrips populations, tobacco thrips populations, tospovirus.
The genus Tospovirus (family Bunyaviridae) consists of some highly destructive plant viruses that are transmitted by at least eight thrips species (Thysanoptera: Thripidae) (7). Tospoviruses are acquired only by larvae (28) and are transmitted by second larval instars and adults (32). Transmission occurs after a latent period (LP) in which the virus circulates and multiplies in the vector $(27,34)$. The virus is transstadially passed in the vector, retained during its whole life span, but not transovarially transmitted to its progeny (31).

Tomato spotted wilt virus (TSWV), the type species of the genus Tospovirus (13), has a worldwide distribution, a host range that exceeds 1,000 botanical plant species (D. Peters, unpublished data), and causes economic losses in many crops (7). Shortly after the first description of TSWV, the onion thrips, Thrips tabaci Lindeman, was identified as a vector (19). Although T. tabaci was considered an important vector for many decades (21), several researchers have recently demonstrated in laboratory studies that some populations transmit TSWV poorly or not at all $(6,16,17)$. In contrast, Lemmetty and Lindqvist (8) reported consistent, efficient transmission of TSWV by T. tabaci. TSWV epidemics in tobacco in Southeast Europe have been attributed to T. tabaci because this is the only thrips species detected in tobacco crops $(5,25,35)$, further showing the TSWV vectoring capacity of the insect.

Corresponding author: N. I. Katis; E-mail address: katis@ agro.auth.gr

Publication no. P-2002-0415-02R

(c) 2002 The American Phytopathological Society
T. tabaci populations vary in their reproductive strategy, using parthenogenesis or sexual reproduction. Thelytokous populations consist of only females, which reproduce parthenogenetically, whereas arrhenotokous populations consist of both males and females. The arrhenotokous type reproduces sexually; the diploid females are produced from fertilized eggs and the haploid males from unfertilized eggs (9). Recent studies showed that arrhenotokous populations of $T$. tabaci from leek transmit TSWV inefficiently $(2,30)$, whereas thelytokous populations did not transmit (30) or transmitted poorly (24). These studies suggest that there may be considerable diversity in the ability of $T$. tabaci populations to transmit TSWV, and that host preference and reproductive strategies may play a role in this diversity.

The aims of this study were to analyze the vector ability of thelytokous and arrhenotokous populations of T. tabaci from leek and tobacco. In addition, the ability of the T. tabaci populations collected from tobacco in Greece was described in terms of the developmental stage at which thrips acquire and transmit TSWV, and the median acquisition access period (AAP), LP, and inoculation access period (IAP) of males and females.

\section{MATERIALS AND METHODS}

Thrips. Two thelytokous populations of T. tabaci from onion plants (one, Tt-J, was supplied by T. Murai, Japan, and the other, Tt-NL, was collected in The Netherlands) and an arrhenotokous $T$. tabaci population (Tt-4) collected from a leek plant in Greece (2) were maintained on leek in glass jars. Two arrhenotokous $T$. tabaci populations from Greece, one designated Tt-1, originated 
from Thessaloniki, and the other, Tt-2, from Komotini, were collected from tobacco crops heavily infected with TSWV. These populations were reared on leek for three generations and then transferred to tobacco (Nicotiana tabacum cv. Basmas) plants in thrips-proof cages. A Frankliniella occidentalis culture, infesting a greenhouse bean crop in The Netherlands, was reared on bean pods (Phaseolus vulgaris cv. Prelude). Thrips isolates were kept at $25 \pm 1^{\circ} \mathrm{C}$ and under a 16-h photoperiod (18).

TSWV isolate and plant material. A Greek TSWV isolate from a tobacco plant in Thessaloniki that was identified by enzymelinked immunosorbent assay (ELISA) and host range tests was used in these studies. The original inoculum, stored at $-80^{\circ} \mathrm{C}$, was sap-inoculated to $N$. tabacum cv. Basmas and Datura stramonium plants, from which the thrips larvae could acquire virus 2 weeks after inoculation.

The infectivity of thrips was tested on leaf disks from 3- to 6-week-old healthy Petunia $\times$ hybrida cv. Blue Magic, and from 2- to 3-week-old healthy $D$. stramonium and $N$. tabacum cv. Basmas plants. Plants were kept in dark for $24 \mathrm{~h}$ prior to sap or thrips inoculation in order to enhance their susceptibility to infection (1).

Determination of the reproductive strategy of the $T$. tabaci populations. The sex of the offspring produced from unfertilized eggs was determined by individually placing pupae of each $T$. tabaci population on D. stramonium leaves on $1 \%$ Bacto agar (Scharlam Microbiology, Barcelona) with $0.03 \%$ benzimidazole (Sigma-Aldrich Chemic GmbH, Munich) in plastic petri dishes. The emerging males were discarded, whereas 10 females of each population were allowed to oviposit on $D$. stramonium leaves. These females were transferred to fresh leaves every 3 days until they died. The emerging larvae were reared until they became adult and their sex could be recorded.

Transmission efficiency. Larvae less than 24-h old were placed on infected $N$. tabacum or D. stramonium leaves in Tashiro cages, where they could acquire TSWV during the whole larval stage or the indicated period. The transmission efficiency of the adults was tested 1 day after emergence in three IAPs of $48 \mathrm{~h}$ on leaf disks of petunia, D. stramonium, or N. tabacum in Eppendorf tubes (32). The sex of these thrips was also recorded. When infectivity was tested with a series of disks of the three different plant species, a Latin square design was used to eliminate thrips age and host effects on the transmission for the three IAPs given. Petunia leaf disks, floating on water, were incubated for 3 days and the other leaf disks for 5 days at $25^{\circ} \mathrm{C}$ in 24 -well plates (Costar Europe Ltd., Badhoevedorp, The Netherlands). Infection of the petunia disks was evaluated by the appearance of local lesions, whereas infection of the tobacco and D. stramonium was assessed by double-antibody sandwich (DAS)-ELISA. All experiments were performed at $25 \pm 0.5^{\circ} \mathrm{C}$ with a 16-h photoperiod. Experiments consisted of two, three, or four replications. Results were analyzed by one-way analysis of variance, and mean separation was performed using Duncan's multiple range tests among hosts and Student's $t$ test between males and females.

T. tabaci infectivity from naturally TSWV-infected tobacco crops. T. tabaci populations were collected from naturally infect- ed tobacco plants from several tobacco growing areas in Greece and their infectivity was tested on petunia leaf disks.

T. tabaci host preference. The ability of all thrips populations to colonize tobacco plants was studied by placing groups of 25 adults on two four-leaf tobacco plants in thrips-proof cages. The plants were monitored every day for the presence of thrips. After a period of 5 weeks, tobacco plants were cut into pieces and checked for the presence of larvae and adults. In another experiment, 10 adults were individually placed on a tobacco leaf disk or on a piece of leek leaf on agar in petri dishes, as described previously, at $25 \pm 0.5^{\circ} \mathrm{C}$ (light/dark, 16/8 h). The dishes were checked daily for adult and larvae presence for more than 1 month. Both experiments were repeated four times.

Relationship between larval age and ability to acquire TSWV. The ability of developing larvae to successfully acquire TSWV was tested by placing newly hatched and 1-, 2-, 3-, 4-, and 5 -day-old larvae of the tobacco population Tt-1 on infected tobacco leaves at $25 \pm 0.5^{\circ} \mathrm{C}$ until they pupated. First instar larvae less than 24-h old were placed either directly on the infected tobacco leaves or on virus-free tobacco leaves until they were transferred to infected leaves for virus acquisition. Transmission efficiency of the adults was determined in three IAPs on petunia leaf disks. Age cohorts of 30 thrips were used in each of the three replications performed. Ten thrips of each age cohort kept on healthy plant material served as controls.

Determination of the median AAP. The median AAP $\left(\mathrm{AAP}_{50}\right)$, the period at which $50 \%$ of the exposed larvae successfully acquire the virus, was estimated for Tt- 1 thrips. Larvae less than 24-h old were placed for 5, 10, 20, 40, 80, 160, 320, 640, 1,280, or 2,560 min on tobacco leaves infected with TSWV in Tashiro cages at $25^{\circ} \mathrm{C}$. In addition, one group of larvae was left on infected tobacco leaves for their entire larval period to determine the maximum acquisition rate. After the AAPs, the larvae were transferred to healthy tobacco leaves to complete their development. Ten larvae confined on healthy tobacco leaves served as controls. For each AAP, an average of 25 adults was tested for their infectivity on petunia leaf disks in each of the four repeats. To calculate the relative efficiencies, the transmission rate of the thrips, which had

TABLE 2. The proportion (percent) of viruliferous individual thrips of Thrips tabaci populations collected in Tomato spotted wilt virus (TSWV)infected tobacco fields as assayed by petunia leaf disk system

\begin{tabular}{lcccc}
\hline & \multirow{2}{*}{$\begin{array}{c}\text { TSWV incidence in } \\
\text { Region }\end{array}$} & \multicolumn{3}{c}{$\%{\text { Viruliferous T. } \text { tabaci }^{\mathrm{z}}}^{\mathrm{y}}$} \\
\cline { 3 - 5 } & tobacco crops (\%) & Males & Females & Total \\
\hline Thessaloniki & 100 & $0(1)$ & $17(77)$ & $17(78)$ \\
Thessaloniki & 100 & $0(0)$ & $25(110)$ & $25(110)$ \\
Komotini = Tt-1 & 100 & $40(5)$ & $50(28)$ & $49(33)$ \\
Komotini & 100 & $36(33)$ & $46(37)$ & $41(70)$ \\
Kilkis & 45 & $27(11)$ & $10(97)$ & $12(108)$ \\
Kilkis = Tt-2 & 100 & $25(4)$ & $33(112)$ & $33(116)$ \\
Kilkis & 100 & $0(1)$ & $29(115)$ & $29(116)$ \\
Giannitsa & 100 & $50(6)$ & $22(109)$ & $24(115)$ \\
\hline
\end{tabular}

y Fields in the same region are at different locations.

${ }^{\mathrm{z}}$ Number of thrips tested in parenthesis.

TABLE 1. Thrips tabaci populations used in the study; their host plant origin, reproductive strategy, and host preference

\begin{tabular}{|c|c|c|c|c|}
\hline \multirow[b]{2}{*}{ Population } & \multirow[b]{2}{*}{ Host plant } & \multirow[b]{2}{*}{ Reproductive strategy ${ }^{z}$} & \multicolumn{2}{|c|}{ Host preference } \\
\hline & & & Leek & Tobacco \\
\hline T. tabaci $\mathrm{Tt}-\mathrm{NL}$ & Leek & Thelytoky & Development of populations & Larvae and adults died within 2 or 3 days \\
\hline T. tabaci Tt-J & Leek & Thelytoky & Development of populations & Larvae and adults died within 2 or 3 days \\
\hline T. tabaci Tt-4 & Leek & Arrhenotoky & Development of populations & One or two larvae were irregularly observed \\
\hline T. tabaci Tt-1 & Tobacco & Arrhenotoky & Development of populations & Development of populations \\
\hline T. tabaci $\mathrm{Tt}-2$ & Tobacco & Arrhenotoky & Development of populations & Development of populations \\
\hline
\end{tabular}

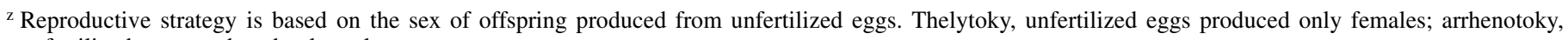

unfertilized eggs produced only males. 
spent their entire larval development on infected leaves, was transformed to $100 \%$ by excluding the nontransmitters.

Determination of the median LP. The median LP $\left(\mathrm{LP}_{50}\right)$ was defined as the period between the start of the AAP and the end of that IAP in which $50 \%$ of the vectors made cumulatively a first transmission. Tt-1 larvae, less than 24-h old, were given an AAP of $48 \mathrm{~h}$ at $20 \pm 0.5,24 \pm 0.5$, and $27 \pm 0.5^{\circ} \mathrm{C}$. After these AAPs, each larvae was individually tested for its ability to transmit TSWV at 24-h intervals on fresh petunia leaf disks until they pupated. The emerging adults were also tested on petunia leaf disks at 24-h intervals for 6 days. During the entire experiment, the thrips were kept at the temperatures at which they acquired the virus. The $\mathrm{LP}_{50}$ was determined using 24, 31, and 34 males and 26, 59, and 64 females at 20,24 , and $27^{\circ} \mathrm{C}$, respectively. Ten larvae, caged on virus-free tobacco plants, were used as controls at each temperature.

Determination of the median IAP. The median IAP $\left(\operatorname{IAP}_{50}\right)$, defined as the feeding period at which $50 \%$ of the viruliferous thrips transmit, was also determined. Tt-1 larvae were confined on tobacco leaves infected with TSWV for their entire larval stage. Viruliferous adults were selected after an IAP of $24 \mathrm{~h}$ on petunia leaf disks and the development of local lesions after 2 to 3 days of incubation. The adults that transmitted TSWV to the disks were used to transmit TSWV in IAPs of 5, 10, 20, 40, 80, 160, 320, $640,1,280$, or $2,560 \mathrm{~min}$ at $25 \pm 0.5^{\circ} \mathrm{C}$ on petunia or tobacco leaf disks. An average of 50 thrips was tested in two repeats for each IAP. In addition, 10 healthy thrips per IAP were tested on petunia or tobacco leaf disks as controls.

Calculation of the $\mathbf{L P}_{\mathbf{5 0}}, \mathbf{A A} \mathbf{P}_{\mathbf{5 0}}$, and $\mathbf{I A P} \mathbf{P}_{\mathbf{5 0}}$. The percentages of thrips transmitting virus were used to estimate the $\mathrm{AAP}_{50}$ and IAP $_{50}$ and their $95 \%$ fiducial limits (FL) by log-probit analysis (3). The cumulative first transmissions were used to estimate the LP $_{50}$ and its FL. Data were processed and analyzed with SPSS-9 computer program (SPSS Inc., Chicago).

ELISA. After inoculation by thrips, infection of tobacco and $D$. stramonium leaf disks by TSWV was monitored by DAS-ELISA (32) using polyclonal antibodies $(1 \mu \mathrm{g} / \mathrm{ml})$ raised against the nucleocapsid protein of TSWV. The extracts were prepared by grinding $15 \mathrm{mg}$ of leaf tissue in $1 \mathrm{ml}$ of phosphate-buffered saline with Tween $20\left(0.14 \mathrm{M} \mathrm{NaCl}, 1 \mathrm{mM} \mathrm{KH} \mathrm{PO}_{4}, 8 \mathrm{mM} \mathrm{NaHPO}\right.$, $2.5 \mathrm{mM} \mathrm{KCl}$, and $0.05 \%$ Tween 20). The absorbance values, read on an ELISA reader (EL 312; Bio-Tek Instruments, Greiner BV, Alphen aan de Rijn, The Netherlands) at $405 \mathrm{~nm}$, were corrected for blank values obtained from wells filled with buffer in the sample incubation step. Samples with readings higher than the average of healthy control plus three times their standard deviation were considered positive.

\section{RESULTS}

Determination of the reproductive strategy of the $T$. tabaci populations. The thelytokous nature and the parthenogenetic mode of reproduction of $T$. tabaci populations Tt-J and Tt-NL was established by the absence of any male in these populations or in their offspring produced from unfertilized eggs. The population Tt-4 from leek and all sampled populations from tobacco plants consisted of both males and females. Unfertilized eggs produced only males, consistent with their arrhenotoky and sexual reproductive strategy. Thelytokous populations were not detected on tobacco (Table 1).

T. tabaci infectivity from naturally TSWV-infected tobacco crops. T. tabaci adults, collected on tobacco plants naturally infected with TSWV in different areas of Greece, transmitted TSWV at rates varying from 16.7 to $48.5 \%$. Transmission rates did not depend on the TSWV incidence in the fields, because all sampled fields, apart from one, were completely infected (Table 2).

Transmission of TSWV by arrhenotokous $T$. tabaci maintained on tobacco. The populations Tt-1 and Tt-2 (Table 2) were selected for further study because they were efficient transmitters of TSWV and they originated from different regions. These populations, when reared on tobacco for several generations, transmitted TSWV at rates between 50 and $67 \%$, regardless of the host (tobacco or D. stramonium) from which the larvae acquired the virus and completed their larval development (Table 3).

Transmission of TSWV by an arrhenotokous T. tabaci population from leek. An arrhenotokous T. tabaci (Tt-4) population, collected from and reared on leek, and acquiring TSWV from $D$. stramonium, transmitted the virus at an overall average of $3.1 \%$. Transmission rates were similar on petunia, tobacco, or $D$. stramonium leaf disks $(F=0.77 ; \mathrm{df}=2$ and $3 ; P=0.54)$ (Table 4$)$. Because all larvae died on tobacco, virus acquisition from this host could not be determined.

Transmission of TSWV by thelytokous T. tabaci populations. None of the 200 tested thrips from each of the thelytokous populations Tt-J and Tt-NL from leek was able to transmit TSWV to petunia, tobacco, or D. stramonium leaf disks after feeding on infected D. stramonium. In contrast, $49 \%$ of $F$. occidentalis individuals that fed on infected $D$. stramonium transmitted the virus to petunia leaf disks.

T. tabaci host preference. All adults of the thelytokous populations Tt-J and Tt-NL and the arrhenotokous population Tt-4 from leek died within 3 days when kept on tobacco leaves in petri dishes. In addition, no larvae or adults of the thelytokous populations were found after 1 month on the tobacco plants. When tobacco plants were infested with thrips of the arrhenotokous population Tt-4 from leek, only one or two larvae were occasionally found. The populations from tobacco proliferated well on tobacco leaves in petri dishes and on intact tobacco plants, and thrived on leek leaf material in petri dishes (Table 1).

Relationship between larval age and ability to acquire TSWV. The percentage of adults that transmitted TSWV decreased with

TABLE 4. Transmission of Tomato spotted wilt virus by an arrhenotokous leek population of Thrips tabaci (Tt-4) after being acquired from Datura stramonium

\begin{tabular}{lccc}
\hline & \multicolumn{3}{c}{$\%$ Transmission efficiency $^{z}$} \\
\cline { 2 - 4 } Inoculation host & Males & Females & Total \\
\hline D. stramonium & $0.0 \mathrm{a}(10)$ & $1.5 \mathrm{a}(138)$ & 1.4 a (148) \\
Petunia $\times$ hybrida cv. Blue Magic & $10.5 \mathrm{ab}(19)$ & $2.1 \mathrm{a} \mathrm{(143)}$ & $3.1 \mathrm{a}(162)$ \\
Nicotana tabacum cv. Basmas & $14.3 \mathrm{~b}(21)$ & $0.7 \mathrm{a} \mathrm{(146)}$ & $2.4 \mathrm{a}(167)$ \\
\hline
\end{tabular}

${ }^{\mathrm{z}}$ Efficiencies followed by the same character within a column did not differ significantly $(P<0.05)$ according to one-way analysis of variance, Duncan's test. The number of adults tested is given in parenthesis.

TABLE 3. Transmission of Tomato spotted wilt virus by the tobacco Thrips tabaci populations Tt-1 and Tt-2 to Petunia $\times$ hybrida cv. Blue Magic leaf disks

\begin{tabular}{|c|c|c|c|c|}
\hline \multirow[b]{2}{*}{ Population } & \multirow[b]{2}{*}{ Virus source } & \multicolumn{3}{|c|}{ Transmission efficiency $(\%)^{\mathrm{z}}$} \\
\hline & & Males & Females & Total \\
\hline T. tabaci Tt-1 & $\begin{array}{l}\text { Nicotiana tabacum cv. Basmas } \\
\text { Datura stramonium }\end{array}$ & $\begin{array}{l}62.0(42) \\
57.0(21)\end{array}$ & $\begin{array}{l}50.0(14) \\
100.0(6)\end{array}$ & $\begin{array}{l}58.9(56) \\
66.7(27)\end{array}$ \\
\hline T. tabaci $\mathrm{Tt}-2$ & $\begin{array}{l}\text { N. tabacum cv. Basmas } \\
\text { D. stramonium }\end{array}$ & $\begin{array}{c}66.7(105) \\
n t\end{array}$ & $\begin{array}{c}56.4(55) \\
\mathrm{nt}\end{array}$ & $\begin{array}{l}63.1(160) \\
n t\end{array}$ \\
\hline
\end{tabular}

${ }^{\mathrm{z}}$ Number of thrips tested in parenthesis. nt, not tested. 
the age at which the larvae were allowed to acquire TSWV from infected tobacco. The highest efficiency $(61 \%$ for males and $51 \%$ for females) was observed when newly hatched larvae were exposed to the virus. A few adults transmitted when TSWV was acquired by 3 - to 4-day-old male larvae (18\%) and 4- to 5-day-old female larvae (1\%) (Fig. 1).

Determination of the median AAP. Transmission efficiency of TSWV for both sexes was positively correlated with the length of the AAP on infected tobacco leaves (Fig. 2). The virus was acquired by $9.2 \%$ of the female larvae in $5 \mathrm{~min}\left(\mathrm{AAP}_{\min }\right)$ and $4 \%$ of the male larvae in $10 \mathrm{~min}$. Females reached the optimum transmission rates $(53 \%)$ after an AAP of $21 \mathrm{~h}\left(\mathrm{AAP}_{\mathrm{opt}}\right)$, whereas for males $(87.5 \%)$ it was $43 \mathrm{~h}$.

An $\mathrm{AAP}_{50}$ of $41 \mathrm{~min}$ (95\% FL: 29 to $\left.55 \mathrm{~min}\right)$ was calculated for the whole population of $T$. tabaci. These values were $65 \mathrm{~min}(95 \%$ FL: 35 to $189 \mathrm{~min}$ ) and $35 \mathrm{~min}$ (95\% FL: 20 to $54 \mathrm{~min}$ ) for males and females, respectively.

Determination of the median LP. After virus acquisition as newborn larvae, 25, 8, and $8 \%$ of larvae transmitted TSWV before pupation when kept at 20,24 , and $27^{\circ} \mathrm{C}$, respectively. After determining their sex when these larvae became adults, it was found that male $(F=20.8 ; \mathrm{df}=2$ and $6 ; P<0.01)$ as well as female $(F=$ 47.6; $\mathrm{df}=2$ and $6 ; P<0.01)$ larvae transmitted more efficiently when kept at $20^{\circ} \mathrm{C}$ versus 24 or $27^{\circ} \mathrm{C}$. The percentage of male larvae that transmitted was $17.9,6.3$, and $7.3 \%$, whereas that of

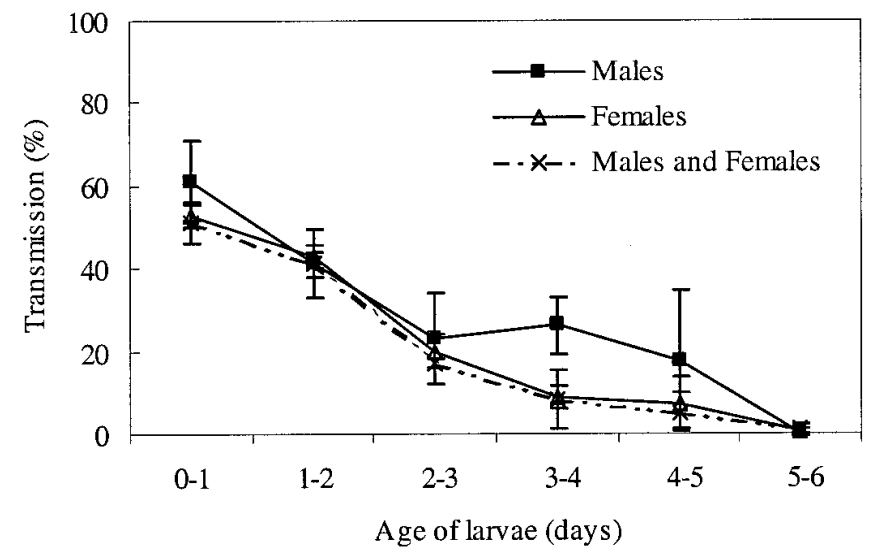

Fig. 1. The average rates (percent) and standard errors by which Thrips tabaci Tt-1 transmitted Tomato spotted wilt virus to Petunia $\times$ hybrida cv. Blue Magic leaf disks as a function of the age at which the larvae acquired the virus from Nicotiana tabacum $\mathrm{cv}$. Basmas until pupation.

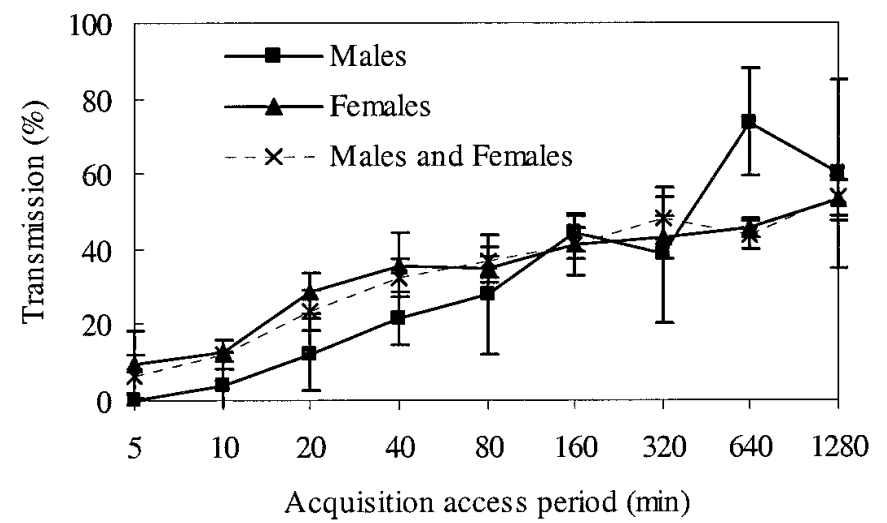

Fig. 2. The average rate (percent) and standard errors of Tomato spotted wilt virus transmission by Thrips tabaci Tt-1 as a function of the acquisition access period. Virus was acquired by 0 - to 24-h-old larvae from Nicotiana tabacum cv. Basmas leaves and transmitted by the adults to Petunia $\times$ hybrida cv. Blue Magic leaf disks. female larvae was $20.7,4.9$, and $4.8 \%$ at 20,24 , and $27^{\circ} \mathrm{C}$, respectively (Fig. 3). The number of $T$. tabaci $\mathrm{Tt}-1$ larvae that transmitted TSWV was too low to calculate the $\mathrm{LP}_{50}$.

After becoming adults, 54, 64, and $67 \%$ of them transmitted TSWV, respectively, at these temperatures. The first transmissions by adults were recorded after 13, 9, and 8 days for males and 14, 10 , and 8 days for females at 20,24 , and $27^{\circ} \mathrm{C}$, respectively. The overall rates were $45,54.6$, and $64.6 \%$ for males and 53.6, 65.5, and $67.2 \%$ for females at these respective temperatures (Fig. 3). Transmission rates at $20^{\circ} \mathrm{C}$ were significantly lower than those at 24 and $27^{\circ} \mathrm{C}(F=6.2 ; \mathrm{df}=2$ and $6 ; P<0.05)$. The cumulative percentage of adult thrips transmitting for the first time showed that both sexes transmitted earlier as the temperature increased (Fig. 4). The $\mathrm{LP}_{50}$ values for the adult stage of both sexes decreased with increasing temperatures and were slightly shorter for males than for females. These values were 351 (FL: 343 to $358 \mathrm{~h}$ ), 280 (FL: 276 to $285 \mathrm{~h}$ ), and $223 \mathrm{~h}$ (FL: 219 to $226 \mathrm{~h}$ ) for males, and 405 (FL: 401 to $410 \mathrm{~h}$ ), 310 (FL: 306 to $315 \mathrm{~h}$ ), and $241 \mathrm{~h}$ (FL: 234 to $248 \mathrm{~h}$ ) for females when maintained at 20, 24, and $27^{\circ} \mathrm{C}$, respectively. These values for the whole population were 378 (FL: 373 to 383 h), 300 (FL: 295 to 304 h), and 235 h (FL: 235 to $239 \mathrm{~h}$ ) at these temperatures.

Determination of the median IAP. Viruliferous males or females infected tobacco and petunia leaf disks in IAPs as short as 5 or $10 \mathrm{~min}$. The transmission rate increased with the inoculation period on tobacco (male: $F=14.9$, and female: $F=42.4$; df $=9$ and 10, respectively; $P<0.01$ ) and on petunia (male: $F=9.5$, and female: $F=119.6$; df $=9$ and 10, respectively; $P<0.01$ ) (Fig. 5). On both hosts, the optimum transmission was reached after an IAP of 1,280 min (IAP ${ }_{\text {opt }}$ ) for males and 2,560 min for females (Fig. 5). The $\mathrm{IAP}_{50}$ was $246 \mathrm{~min}$ to tobacco and $365 \mathrm{~min}$ to petunia for males and 96 and 345 min for females. Transmission to tobacco was more efficient than to petunia only when challenged by viruliferous females in an IAP of $80(t=37.6$; $\mathrm{df}=1 ; P<0.05)$ or $160 \mathrm{~min}(t=28.2 ; \mathrm{df}=1 ; P<0.05)$, whereas males transmitted the virus to both hosts with the same efficiency.

\section{DISCUSSION}

This study strengthens the hypothesis that $T$. tabaci represents a complex of populations differing in reproductive strategy, host preference, and the ability to transmit TSWV. In field studies on the spread of TSWV by T. tabaci, Zawirska (36) concluded that this species consists of two subspecies. One, T. tabaci sp. tabaci, reproduces sexually, specializes on tobacco, and vectors TSWV. The other subspecies, T. tabaci sp. communis, reproduces
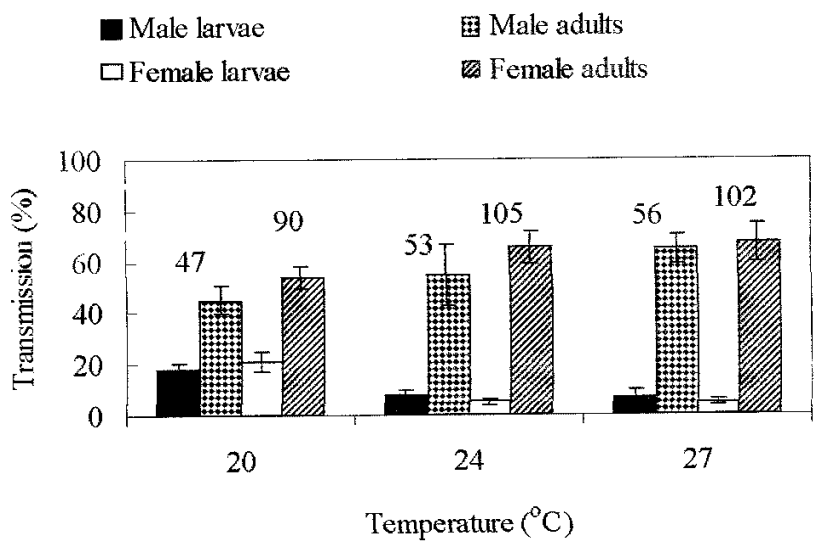

Fig. 3. Partition of Tomato spotted wilt virus transmission efficiency of male and female Thrips tabaci Tt- 1 larvae and adults at 20,24 , and $27^{\circ} \mathrm{C}$. Virus was acquired by 0 - to 24-h-old larvae for $48 \mathrm{~h}$ from Nicotiana tabacum cv. Basmas and transmitted to Petunia $\times$ hybrida $\mathrm{cv}$. Blue Magic leaf disks. The number of thrips tested is given above the columns. 
parthenogenetically, does not prefer to feed on tobacco, and fails to transmit TSWV.

Our results confirm that the $T$. tabaci complex consists of thelytokous and arrhenotokous populations showing large differences in their preference for tobacco. The arrhenotokous populations collected on tobacco were efficient transmitters and reproduced well both on tobacco and leek, even when they were kept for several generations on tobacco in the laboratory. However, vector ability and host specificity of these populations differed considerably from the arrhenotokous populations collected on leek and bean $(2,30)$. Only a few individuals of the latter populations transmitted the virus after acquisition, whereas these populations survived poorly or not at all on tobacco. Thelytokous populations collected on onion and grown on leek proved to be nonvectors (30) and failed to feed on tobacco. However, transmission of TSWV by a thelytokous population, although at a low rate, has recently been reported (24).

The great variability in the spread of TSWV in different geographic regions can be explained by the distribution of the different T. tabaci populations. The arrhenotokous populations, which prefer tobacco as host, are efficient vectors and are responsible for the devastating spread of TSWV in Eastern Europe $(5,25,35)$. The thelytokous populations, being poor or nonvectors of TSWV, seem to prevail in West Europe and North America (9), where several researchers failed to record transmission by $T$. tabaci. The inability of those populations to infest tobacco can explain why, instead of T. tabaci, F. fusca is the main vector of this virus in tobacco crops in the United States (12).

Little is known about the factors determining the efficiency of the various $T$. tabaci populations to transmit TSWV and the development of the infection in thrips. Recent studies suggest that the ability to transmit TSWV depends on the time at which the virus reaches and infects the salivary glands. Transmission of the virus by larvae (22,32, this study), the presence of the virus in salivary glands of the transmitting larvae and adults, and the absence of infected salivary glands in nontransmitting adults strongly suggests that the virus has to reach these glands before pupation (15). The inability of a thelytokous $T$. tabaci population to transmit TSWV is evidently associated with the absence of any virus signal in the salivary glands (14).

The exclusive ability of the larvae to acquire the virus is a feature that distinguishes TSWV-T. tabaci transmission from that of other virus-vector systems $(10,11,21,28)$. The present results show that both first ( 0 to 2 days old) and second instar larvae ( 2 to

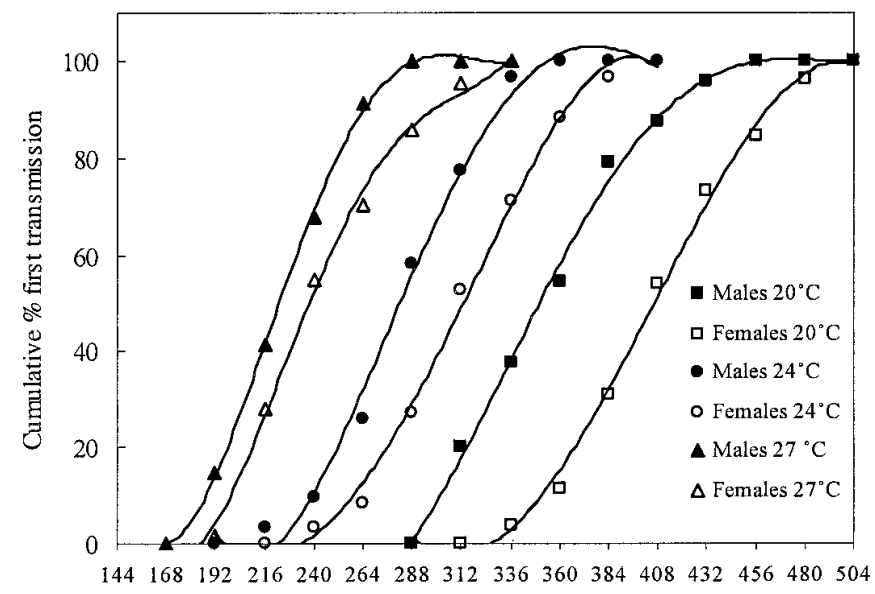

Time in hours

Fig. 4. The cumulative percentage of Thrips tabaci Tt-1 adults transmitting Tomato spotted wilt virus for the first time plotted against time at 20, 24, and $27^{\circ} \mathrm{C}$. Virus was acquired by 0 - to 24 -h-old larvae for $48 \mathrm{~h}$ from Nicotiana tabacum cv. Basmas and transmitted to Petunia $\times$ hybrida cv. Blue Magic leaf disks.
6 days old) (9) acquire the virus and that second instar larvae and adults transmit it. However, the ability of the larvae to acquire the virus rapidly decreases with their age. Such a decrease has also been shown for $F$. occidentalis $(15,26,29)$. Van de Wetering et al. (28) identified an F. occidentalis population in which the ability to acquire TSWV was restricted to first instar larvae.

Long AAPs, required to ingest an infective dose of virus, have been reported (11). However, recent studies show that the minimum AAP is approximately 5 min (33, this study) for different tospovirus-vector combinations. Viruliferous thrips can also successfully infect in IAPs as short as $5 \mathrm{~min}$. These relatively short AAPs and IAPs indicate that individual thrips can ingest and transmit an infective dose in very short periods, and that infected cells and the cells that are to be infected are readily accessible to the vector.

The transmission efficiency increases with the AAP, although not in linear fashion. The $\mathrm{AAP}_{\text {min }}$ was $5 \mathrm{~min}$, whereas the $\mathrm{AAP}_{50}$ was reached in approximately $1 \mathrm{~h}$ and the $\mathrm{AAP}_{\mathrm{opt}}$ in 1 day. Sakimura (21) found a similar trend; transmission of TSWV by $T$. tabaci increased from $4 \%$ in $15 \mathrm{~min}$, to $33 \%$ in $1 \mathrm{~h}$, to $59 \%$ in 1 day, and to $77 \%$ in 4 days. The $\mathrm{AAP}_{\text {opt }}$ found in this study was shorter than that previously reported for T. tabaci, but is in good agreement with that reported for $F$. occidentalis (33).

Previous studies showed that TSWV could be transmitted by $T$. tabaci larvae and adults after a minimum LP of 3 (20), 4 (22), and 5 days (23). The present study confirmed that $T$. tabaci larvae can also transmit the virus. Larvae kept at $20^{\circ} \mathrm{C}$ transmitted TSWV at a rate of $25 \%$, whereas a rate of only $7 \%$ was found when they were kept at $27^{\circ} \mathrm{C}$. A similar temperature-dependent trend was also observed in the transmission of TSWV and Impatiens necrotic spot virus (INSV) by F. occidentalis larvae (32), although the transmission rates were considerably higher. Notwithstanding that the larvae of $T$. tabaci can transmit TSWV and those of $F$. occidentalis TSWV and INSV, the predominant spread in the field will be by adults because they are more mobile than larvae (9).
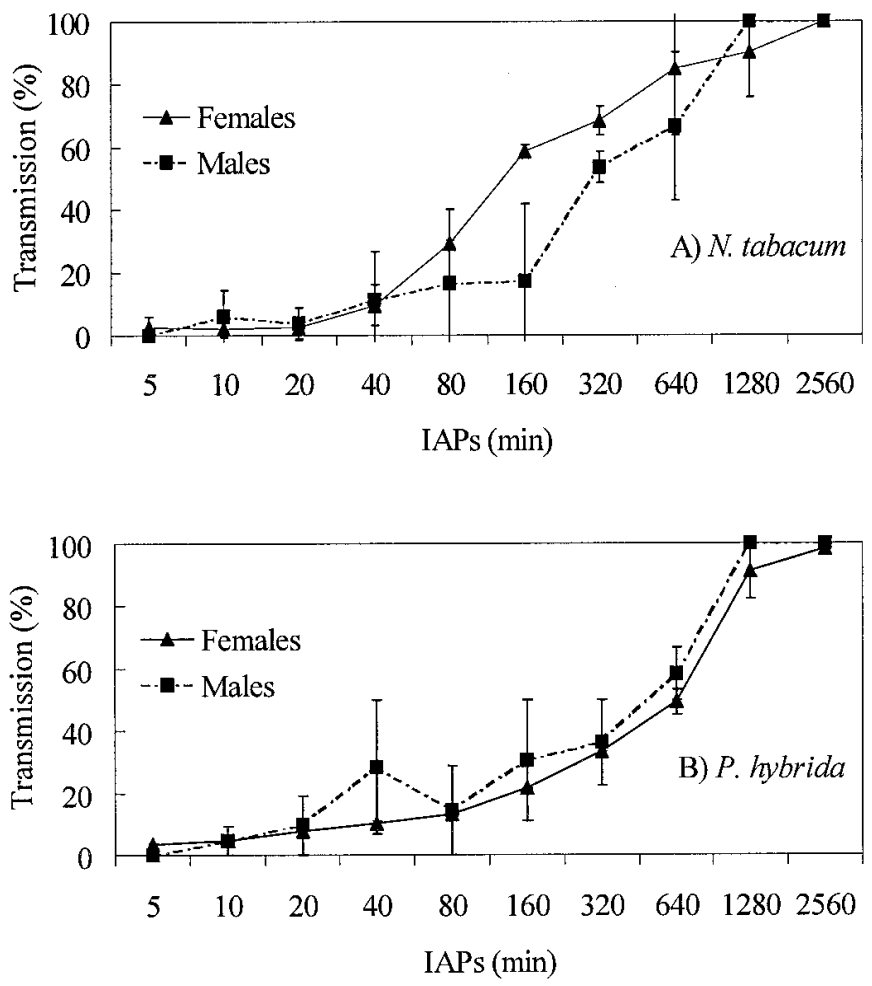

Fig. 5. The efficiency and standard errors of Tomato spotted wilt virus transmission by viruliferous Thrips tabaci Tt-1 adults after different inoculation access periods (IAPs) on healthy leaf disks of A, Nicotiana tabacum cv. Basmas and B, Petunia $\times$ hybrida cv. Blue Magic. 
The percentage of T. tabaci larvae transmitting TSWV was considerably lower than that of $F$. occidentalis (32). The difference may be attributed to the techniques applied. T. tabaci larvae were 0 - to 24-h old when given access to the virus, whereas the $F$. occidentalis larvae were 0 - to 4 -h old. This difference in age at which the virus was first acquired may explain why $T$. tabaci larvae were less successful in the acquisition of the virus. The virus is then expected to reach the salivary glands at a later time. In some cases, the interval between the time that the T. tabaci larvae become infective and pupate may be too small to allow TSWV transmission. The lower number of larvae that transmit at higher temperatures is likely to be explained by a more rapid development of thrips. Thus, the interval between becoming infective and pupation will be shorter at higher temperatures than at lower temperatures.

The present study showed that the majority of $T$. tabaci individuals made the first transmission as an adult. The $\mathrm{LP}_{50}$ recorded for $T$. tabaci adults was approximately 9 days for males and 10 days for females at $27^{\circ} \mathrm{C}$, and 15 and 17 days at $20^{\circ} \mathrm{C}$. These values correspond with the value found for a transmitting population of T. tabaci by Sakimura (22). The LPs for F. occidentalis adults have a similar range (32), but these authors calculated the LPs only for the larvae. The time required for larval development, the number of larvae transmitting TSWV, and LP values decreased with increasing temperatures, as was observed for $F$. occidentalis (32).

Viruliferous thrips transmit the virus to various hosts in probes as short as $5 \mathrm{~min}$ but at different rates. The differences observed are probably due to host preference of thrips or susceptibility of the host to the virus. Both are factors that will have an impact on the spread of the virus in the field (4).

Analyzing the transmission of male and female thrips of the tobacco population of T. tabaci showed that both sexes efficiently transmitted TSWV and at similar rates. In contrast, males in the leek populations of this species were more efficient transmitters (2). The LP of the virus in T. tabaci males was slightly shorter than in females, especially at the lower temperatures, possibly due to an earlier emergence of adult males (9).

The transmission characteristics prove that the arrhenotokous populations of $T$. tabaci from tobacco plants are efficient vectors of TSWV. However, the biological relationship of T. tabaci and TSWV is rather complex. The results of this study strongly suggest that the species consists of heterogeneous populations in terms of their ability to transmit TSWV, host preference, and reproductive strategies. Studies on the infection mechanisms and virus pathway in the thrips, on the genetics of the different populations, and on the morphological characters may answer the question whether T. tabaci consists of a complex of populations, subspecies, or different species.

\section{ACKNOWLEDGMENTS}

This research was partially supported by a grant of the Greek Scholarship Foundation to E. K. Chatzivassiliou and by the EC project "Management of insect pests and viruses of tobacco using ecologically compatible technologies." We thank T. Murai for providing us with a $T$. tabaci population.

\section{LITERATURE CITED}

1. Best, R. J. 1968. Tomato spotted wilt virus. Adv. Virus Res. 13:65-146.

2. Chatzivassiliou, E. K., Nagata, T., Peters, D., and Katis, N. I. 1999. The transmission of tomato spotted wilt tospovirus (TSWV) by Thrips tabaci Lind. (Thysanoptera: Thripidae) populations originating from leek. Plant Pathol. 48:700-706.

3. Finney, D. J. 1962. Probit Analysis, a Statistical Treatment of the Sigmoid Response Curve. Cambridge University Press, Cambridge.

4. German, T. L., Ullman, D. E., and Moyer, J. W. 1992. Tospoviruses: Diagnosis, molecular biology, phylogeny, and vector relationships. Annu. Rev. Phytopathol. 30:315-348.
5. Jankowski, F., Slawinski, F. A., Mazur, M., and Micinski, B. 1980. The economic importance of the TSWV in tobacco growing and the results of control of the vector of this disease the tobacco thrips Thrips tabaci Lind. Pages 279-297 in: Proc. XIX Conf. Sci. Inst. Plant Prot., 1979. W. Wegorek and J. J. Lippa, eds. Mater. XIX Sesji Nauk. Inst. Ochr. Rosl., Poznan, Poland.

6. Jones, J. P. 1959. Failure of thrips to transmit an isolate of tomato spotted wilt virus. Phytopathology 49:452-453.

7. Kormelink, R., Peters, D., and Goldbach, R. 1998. Tospovirus genus. No. 363 in: Descriptions of Plant Viruses. M. J. Adams, J. F. Antoniw, H. Barker, A. T. Jones, A. F. Muraut, and D. Robinson, eds. AAB Hort. Res. Inst., Wellesbourne, UK.

8. Lemmetty, A., and Lindqvist, I. 1993. Thrips tabaci (Lind.) (Thysanoptera: Thripidae), another vector for tomato spotted wilt virus in Finland. Agric. Sci. Finl. 2:189-194.

9. Lewis, T. 1973. Thrips-Their Biology, Ecology and Economic Importance. New York Academic Press, London.

10. Lindorf, M. B. 1931. Further studies of the transmission of the pineapple yellow spot virus by Thrips tabaci. Phytopathology 21:999.

11. Lindorf, M. B. 1932. Transmission of the pineapple yellow-spot virus by Thrips tabaci. Phytopathology 22:301-324.

12. McPherson, R. M., Pappu, H. R., and Jones, D. C. 1999. Occurrence of five thrips species on flue-cured tobacco and impact on spotted wilt disease incidence in Georgia. Plant Dis. 83:765-767.

13. Murphy, F. A., Fauquet, G. M., Bishop, D. H. L., Ghabrial, S. A., Jarvis, A. W., Martelli, G. P., Mayo, M. A., and Summers, M. D. 1995. Virus taxonomy. Sixth Report of the International Committee for the Taxonomy of Viruses. Arch. Virol. Suppl. 10:1-586.

14. Nagata, T., Inoue-Nagata, A. K., Goldbach, R., and Peters, D. 2002. Factors determining vector competence and specificity for transmission of Tomato spotted wilt virus. J. Gen. Virol. 83:663-671.

15. Nagata, T., Inoue-Nagata, A. K., Smid, H., Goldbach, R., and Peters, D. 1999. Tissue tropism related to vector competence of Frankliniella occidentalis for tomato spotted wilt virus. J. Gen. Virol. 80:507-515.

16. Paliwal, Y. C. 1974. Some properties and thrips transmission of tomato spotted wilt virus in Canada. Can. J. Bot. 52:1177-1182.

17. Paliwal, Y. C. 1976. Some characteristics of the thrips vector relationship of tomato spotted wilt virus in Canada. Can. J. Bot. 54:402-405.

18. Peters, D., Loomans, A., Nagata, T., Wijkamp, I., and van de Wetering, F. 1998. Methods to rear and maintain thrips in tospovirus transmission studies. Pages 152-159 in: Proc. Invertebrates Captivity Conf., 1997. Tucson, Arizona.

19. Pittman, H. A. 1927. Spotted wilt of tomatoes. J. Austr. Council Sci. Ind. Res. 1:74-77.

20. Razvyaskina, G. M. 1953. The importance of the tobacco thrips in the development of outbreaks of tip chlorosis of Makhorka. (In Russian) Dokl. Vses. Akad. S-Kh. Nauk Im. V. I. Lenica 18:27-31.

21. Sakimura, K. 1962. The present status of thrips-borne viruses. Pages 3340 in: Biological Transmission of Disease Agents. K. Maramorosch, ed. Academic Press, New York.

22. Sakimura, K. 1963. Frankliniella fusca, an additional vector for the tomato spotted wilt virus, with notes on Thrips tabaci, another vector. Phytopathology 53:412-415.

23. Smith, K. M. 1931. Thrips tabaci as a vector of plant virus disease. Nature 127:852-853.

24. Tedeschi, R., Ciuffo, M., Mason, G., Roggero, P., and Tavella, L. 2001. Transmissibility of four tospoviruses by a thelytokous population of Thrips tabaci from Liguria, Northwestern Italy. Phytoparasitica 29:3745.

25. Tsakiridis, J. P., and Gooding, G. V., Jr. 1972. Tomato spotted wilt virus in Greece. Phytopathol. Mediterr. 11:42-47.

26. Ullman, D. E., Cho, J. J., Mau, R. F. L., Westcott, D. M., and Custer, D. M. 1992. A midgut barrier to tomato spotted wilt virus acquisition by adult western flower thrips. Phytopathology 82:1333-1342.

27. Ullman, D. E., German, T. L., Sherwood, J. L., Westcot, D. M., and Cantone, F. A. 1993. Tospovirus replication in insect vector cells: Immunocytochemical evidence that the nonstructural protein encoded by the S RNA of tomato spotted wilt tospovirus is present in thrips vector cells. Phytopathology 83:456-463.

28. van de Wetering, F., Goldbach, R., and Peters, D. 1996. Tomato spotted wilt tospovirus ingestion by first instar larvae of Frankliniella occidentalis is a prerequisite for transmission. Phytopathology 86:900-905.

29. van de Wetering, F., van der Hoek, M., Goldbach, R., Mollema, C., and Peters, D. 1999. Variation in tospovirus transmission between populations of Frankliniella occidentalis (Thysanoptera: Thripidae). Bull. Entomol. Res. 89:579-588.

30. Wijkamp, I., Almarza, N., Goldbach, R., and Peters, D. 1995. Distinct levels of specificity in thrips transmission of tospoviruses. Phytopathology 85:1069-1074.

31. Wijkamp, I., Goldbach, R., and Peters, D. 1996. Virus vector interactions 
of tomato spotted wilt virus in Frankliniella occidentalis is neither accompanied by pathological effects nor by transovarial transmission. Entomol. Exp. Appl. 81:285-292.

32. Wijkamp, I., and Peters, D. 1993. Determination of the median latent period of two tospoviruses in Frankliniella occidentalis, using a novel leaf disk assay. Phytopathology 83:986-991.

33. Wijkamp, I., Van de Wetering, F., Goldbach, R., and Peters, D. 1997. Transmission of tomato spotted wilt virus by Frankliniella occidentalis: Median acquisition and inoculation access period. Ann. Appl. Biol. 129:303-313.
34. Wijkamp, I., Van Lent, J., Kormelink, R., Goldbach, R., and Peters, D. 1993. Multiplication of tomato spotted wilt virus in its insect vector, Frankliniella occidentalis. J. Gen. Virol. 74:341-349.

35. Zawirska, I. 1978. Studies on Thrips tabaci Lindeman (Thysanoptera: Thripidae). Pr. Nauk. Inst. Ochr. Rosl. 2:115-138.

36. Zawirska, I. 1980. Studies on the tobacco thrips (Thrips tabaci Lind.) and its role in the transmission of tomato spotted wilt virus (TSWV) on tobacco. Pages 267-278 in: Proc. XIX Conf. Sci. Inst. Plant Prot., 1979. W. Wegorek and J. J. Lippa, eds. Mater. Sesji Nauk. Inst. Ochr. Rosl., Poznan, Poland. 